\title{
Um caminho para a ciência: a trajetória da botânica Leda Dau
}

\author{
A road to science: the trajectory of the \\ botanist Leda Dau
}

Entrevista e apresentação:

Nara Azevedo, Bianca Antunes Cortes, Magali Romero Sá

Pesquisadoras da Casa de Oswaldo Cruz / Fundação Oswaldo Cruz Av. Brasil 4365 - Prédio do Relógio 21040-900 Rio de Janeiro - RJ Brasil

nazevedo@coc.fiocruz.br; romerosa@coc.fiocruz.br; bcorte@coc.fiocruz.br
DAU, Leda. Um caminho para a ciência: a trajetória da botânica Leda Dau. Entrevista e apresentação, Nara Azevedo, Bianca Antunes Cortes, Magali Romero Sá. Edição, Bianca Antunes Cortes. História, Ciências, Saúde - Manguinhos, Rio de Janeiro, v. 15, supl., p.209-229, jun. 2008.

A entrevista com Leda Dau trata de sua trajetória profissional, dedicada à pesquisa e ao ensino em botânica. Ela trabalhou no Museu Nacional entre 1953 e 1994 e é integrante de uma das primeiras gerações de mulheres a sofrerem o impacto das transformações sociais que, a partir da década de 1920, provocaram mudanças no sistema de gênero brasileiro, bem como possibilitaram a crescente escolarização e profissionalização femininas, viabilizando o seu acesso ao então restrito mundo da ciência.

Palavras-chave: gênero e ciência; história de mulheres; botânica; ecologia; Museu Nacional.

DAU, Leda. A road to science: the trajectory of the botanist Leda Dau. Interviewed and presentation by Nara Azevedo, Bianca Antunes Cortes, Magali Romero Sá. Edited by Bianca Antunes Cortes. História, Ciências, Saúde - Manguinhos, Rio de Janeiro, v. 15, Suppl., p.209-229, June 2008.

This interview with Leda Dau explores her career at the Museu Nacional from 1953 to 1994 and her dedication to research and teaching in the field of botany. She was a member of one of the first generations of women who felt the effects of the social transformations that began in the 1920s. This process brought changes to the gender system in Brazil and improved women's opportunities for schooling and professionalization, thereby allowing them access to the era's restricted world of science.

Keywords: gender and science; women's history; botany; ecology; Brazil's National Museum. 
【eda Dau realizou uma longa e bem-sucedida carreira científica no Museu Nacional $\mathcal{L}$ do Rio de Janeiro. Iniciou suas atividades nessa instituição como estagiária, em 1952, um ano antes de concluir sua formação em história natural, na Faculdade Nacional de Filosofia da Universidade do Brasil (FNFi/UB) - faculdade que teve papel importante na formação de profissionais com carreiras em instituições de pesquisa do Rio de Janeiro. A trajetória profissional de Leda Dau foi marcada pela pesquisa e pelo ensino de botânica, bem como pela ascensão contínua em postos acadêmicos, que culminou em 1986, ao alcançar a direção da instituição centenária, cuja única mulher a dirigir, antes dela, fora a antropóloga Heloisa Alberto Torres.

Neste depoimento, concedido em 2004 à Casa de Oswaldo Cruz/Fundação Oswaldo Cruz $^{1}$, essa filha de imigrantes libaneses nascida em 1924 revela que a educação e a cultura integravam os valores cultivados pela família, em cujas casas sempre houve muitos quintais e jardins, a que atribui o precoce interesse que desenvolveu pelas plantas. Tal interesse foi confirmado durante o curso científico (hoje ensino médio) no Colégio Pedro II, quando vislumbrou a possibilidade de transformar a história natural em profissão.

Sabemos que as aspirações de Leda Dau sustentavam-se nas mudanças sociais e econômicas que marcaram a sociedade brasileira desde a década de 1920 e que alteraram os tradicionais papéis femininos. Na década seguinte, alterações nas políticas educacionais incluíram mudanças substantivas na escolarização feminina, as quais abririam oportunidades inovadoras para a profissionalização de jovens da classe média urbana que, como Leda Dau, passariam crescentemente a ingressar no restrito e masculino mundo da ciência.

Nesse novo cenário social, o Museu Nacional abriria suas portas a estudantes e pesquisadoras, principalmente na botânica, área tradicionalmente reconhecida como feminina e a qual lhes era culturalmente franqueado o acesso desde o século XVIII (Shteir, 1997, p.29; Slack, 1989, p.77). Ao longo dos anos de 1950 e 1960, a Divisão de Botânica incorporou muitas

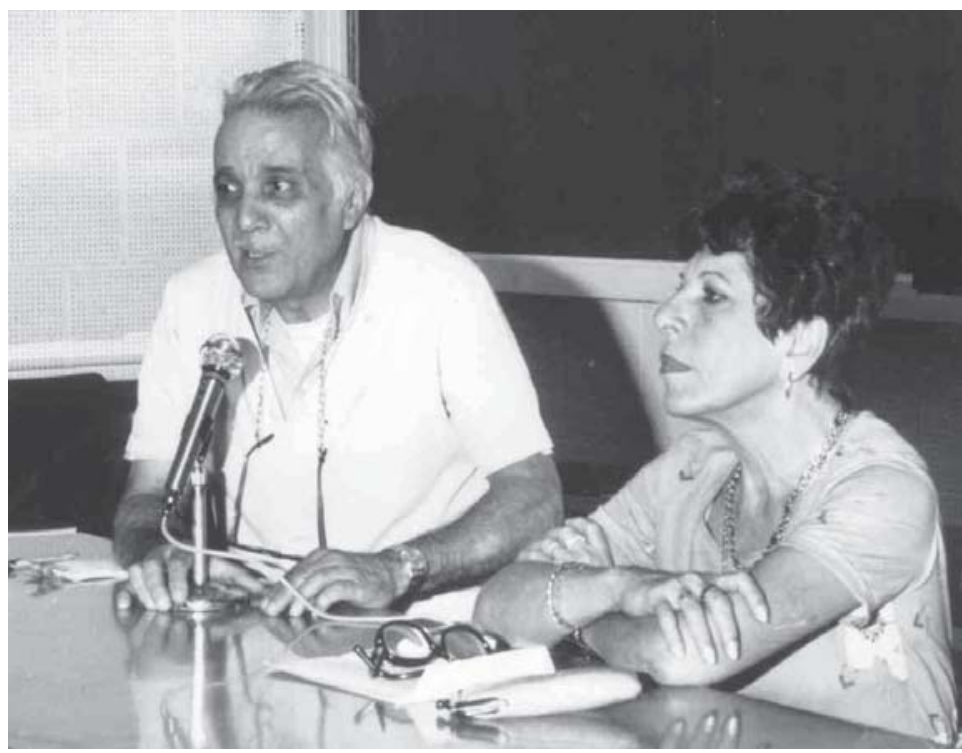

Horácio Macedo e Leda Dau em cerimônia no Museu Nacional jovens interessadas em seguir a carreira de pesquisa, a despeito das dificuldades para o ingresso por meio de concurso público, bem como da ausência de moderna infraestrutura de laboratórios que fosse capaz de assegurar a diversidade nas investigações. Tais limitações conduziriam os novos botânicos a campos emergentes e/ ou mais adequados às circunstâncias locais, como foi o caso da jovem Leda Dau, que começou a atuar no Serviço de Ecologia ainda antes de se formar na FNFi, em 1953.

Criado naquele mesmo ano por Fernando Segadas-Vianna, então pesquisador da Divisão de Botânica, o novo Serviço - que se incorporou formalmente a essa Divisão em 1956 -, tinha como 
propósito fundar uma linha de ação, no Museu, dedicada a estudos de ecologia vegetal voltados para o reconhecimento da vegetação e o levantamento de recursos naturais renováveis e condições ambientais, além de treinar ecologistas. Segadas-Vianna regressara, em 1950, de uma temporada nos Estados Unidos e no Canadá, onde, além de estudar e trabalhar com Stanley A. Cain e Pierre Dansereau, atuou como pesquisador assistente no Cranbrook Institute of Science, em Michigan. Na oportunidade, Segadas-Vianna desenvolveu dissertação de mestrado sob orientação de Cain ${ }^{2}$, inaugurando uma nova abordagem na observação da flora, se comparada aos estudos prioritariamente taxonômicos desenvolvidos no país. Ele iniciara os estudos de ecologia vegetal ao se aproximar do canadense Dansereau, então professor da Universidade de Montreal e já amplamente reconhecido como autoridade nesse campo. Em 1945, a convite do governo brasileiro, Danserau trabalhou por dois anos na Divisão de Botânica do Museu Nacional e ofereceu o curso Os Planos da Biogeografia, que atraiu alunos e pesquisadores de várias instituições do país e era ministrado nas dependências da Divisão de Caça e Pesca do Ministério da Agricultura. ${ }^{3}$ A partir desse curso, Danserau constituiu um pequeno grupo de discípulos ${ }^{4}$, como o próprio Segadas-Vianna, com quem viria a publicar trabalhos ${ }^{5}$, além de Gustavo de Oliveira Castro e Henrique Pimenta-Velloso, pesquisadores do Instituto Oswaldo Cruz, que o auxiliaram em seus estudos sobre os processos de sucessão e colonização da vegetação das restingas e de ambientes de altitude. ${ }^{6}$

O primeiro projeto do Serviço de Ecologia, em que participaram os estudantes Leda Dau, Wilma Ormond, Gisele C. Machline e Jadihel Lorêdo Júnior, foi subvencionado pelo CNPq e recebeu o título Levantamento Ecológico da Vegetação dos Estados da Guanabara e Rio de Janeiro. Tinha como alvo a então inexplorada planície costeira de Cabo Frio, considerada propícia para estudos mesológicos e vegetacionais relacionados à região de restinga. Conforme Leda Dau (1960, p.80), a preocupação fundamental era verificar a aplicabilidade, na vegetação tropical, de teorias, conceitos e métodos desenvolvidos para o estudo de regiões temperadas, para a qual aquela região apresentava vários fatores favoráveis, como a flora relativamente restrita, a vegetação aberta e baixa e comunidades facilmente delimitáveis.

Durante o desenvolvimento do projeto, um número expressivo de espécimes botânicos foram coletados nos diversos ambientes, tendo sido identificadas as entidades biológicas que compunham a área de estudo, o que gerou várias publicações da equipe coordenada por Segadas-Vianna. Em 1960, Leda Dau e Wilma Ormond - já como pesquisadoras concursadas em 1957 - começaram a divulgar, nos Archivos do Museu Nacional, os primeiros resultados dessas investigações: dois trabalhos extensos sobre os microclimas das áreas de restinga e das comunidades vegetais das praias arenosas (Dau, 1960; Ormond, 1960). Cinco anos depois, incentivadas pelos resultados alcançados após os anos de pesquisa na região, as duas, com Segadas-Vianna, decidiram editar pelo Museu Nacional uma série de fascículos independentes, enfeixados sob a denominação Flora ecológica de restingas do Sudeste do Brasil (Segadas-Vianna, Ormond, Dau, 1965-1978). Sem se ater a qualquer seqüência filogenética, as publicações tratavam do material de famílias vegetais específicas, coletadas e enviadas para serem identificadas por especialistas, muitos dos quais escreveram trabalhos para essa série. Vinte e três fascículos vieram a lume ao longo de 14 anos, o que fez da série o mais importante conjunto de divulgação das investigações realizadas pelo emergente grupo de ecologia do Museu Nacional. 
À atividade de pesquisa, Leda Dau somou a de administração científica, iniciada em 1969 quando assumiu a chefia da Divisão de Botânica. Em 1977 prosseguiu nessa trilha, ao ser indicada, pela Congregação do Museu, para ocupar o cargo de vice-diretora. Entre 1980 e 1982, permaneceu como diretora pro tempore da instituição. Em 1986 concorreu à direção do Museu e foi a mais votada de uma lista tríplice, cumprindo o mandato até 1989.

Leda Dau aposentou-se em 1994. Sua trajetória profissional evidencia muitos aspectos das mudanças sociais a que nos referimos anteriormente, em especial aquelas que alteraram a visão, enraizada na cultura patriarcal, de que o casamento e a maternidade constituíam o único e desejável destino para as mulheres. O rompimento de barreiras sociais, juntamente com a ação do Estado - que promoveu reformas na educação e investimento continuado em pesquisa científica a partir de 1951, com a criação do CNPq-, ensejaram o aparecimento de condições institucionais que permitiram tornar a ciência uma opção para um contingente expressivo de mulheres que, valendo-se das estratégias e dos modelos profissionais então disponíveis, contribuíram para a redefinição das balizas que demarcavam as relações de gênero no Brasil.

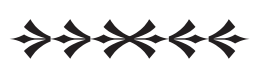

"Meu pai era comerciante. Ele e minha mãe eram pessoas simples, mas

de muita visão, muito abertos, generosos, corretos e íntegros"

\section{Origem familiar}

Professora Leda, quando e onde a senhora nasceu?

Eu nasci em 1924 em Minas Gerais, na cidade de Juiz de Fora. Sou de origem árabe. Meus pais eram libaneses, vieram jovens para o Brasil, com 16 ou 17 anos. Primeiro veio o meu avô, pai de minha mãe, sozinho, procurando melhorar a vida. Depois veio a minha avó materna, Madalena. Minha mãe, Maria, ficou no Líbano com minha bisavó. Depois de um certo tempo as duas vieram também e se juntaram ao meu avô. A minha avó paterna e meu pai vieram um pouco antes da minha mãe. Todos se reuniram e formaram um grupo familiar, para ganhar a vida. Primeiro eles se estabeleceram em Santana do Deserto, onde um de meus irmãos nasceu.

Onde fica essa cidade e por que eles foram para lá?

Fica perto de Juiz de Fora. Eu não sei por que escolheram essa cidade. Mas havia alguns libaneses lá, era uma referência para eles. Logo depois foram para Ubá e em seguida para Juiz de Fora. Mais tarde viemos todos para um subúrbio do Rio de Janeiro, Realengo.

Quando a família veio para o Rio?

Eu era pequena, tinha quatro ou cinco anos.

Qual era a profissão de seu pai?

Meu pai era comerciante. Meu pai e minha mãe eram pessoas simples, mas de muita visão, muito abertos, generosos, corretos e ínte- 
"Minha avó materna ... ficou viúva muito nova e tinha muitos filhos. Meu pai passou a ser o patriarca da família ... Tinha com minha avó uma grande loja de tecidos, calçados, tudo, em Realengo. Essa loja foi fechada e meu pai abriu uma alfaiataria" gros. Tiveram quatro filhos: dois homens e duas meninas. Dois nasceram em Juiz de Fora, outro em Ubá e outro em Cândido Ferreira, que se chamava, à época, Santana do Deserto. Eu fui a última. Hoje só resta eu. Eles nos criaram bem. Inicialmente com certa dificuldade para criar quatro filhos e encaminhá-los, garantir a formação de todos. Cresci nesse ambiente e posso dizer que tive uma vida equilibrada.

Quais os nomes de seus irmãos?

Alberto Dau, o mais velho, Odete e Amaury. Quando viemos para o Rio, cada um começou a estudar, a fazer o ginásio, o científico.

Qual a educação formal de seus pais?

Primária. Sabiam ler e escrever e liam e escreviam bem o árabe.

\section{A senhora sabe falar árabe?}

Aprendi com uma tia que veio do Líbano passar um ano na nossa casa. Meus pais falavam muito o português, porque eram comerciantes, e não nos estimulavam a falar em árabe, o que foi uma falha. Quando essa tia foi embora, aos poucos fui perdendo a fluência do idioma. É uma língua difícil.

\section{O seu pai tinha comércio também aqui no Rio?}

Meu pai ficou com o encargo da minha avó materna, que ficou viúva muito nova e tinha muitos filhos. Ele passou a ser o patriarca da família Dau, que era a dele, e o da família Jará, da minha avó. Tinha com minha avó uma grande loja de tecidos, de calçados, de tudo, em Realengo. Essa loja foi fechada e meu pai abriu uma alfaiataria, que produzia fardamentos militares para a escola de cadetes que havia no bairro e era muito badalada. Quando a escola foi transferida para Pirassununga, abriu-se ali uma escola para sargentos e meu pai passou a fornecer fardamentos para ela. Depois essa escola de formação de sargentos foi transferida para Três Corações, em Minas Gerais, e meu pai foi para lá. Era o único estrangeiro com permissão para trabalhar dentro do quartel, tamanha a credibilidade que ele tinha.

\section{A família foi junto?}

Não. Ele foi sozinho e todo final de semana vinha para o Rio, ou então, nas férias, a gente ia. Lá, ele teve um mal súbito e faleceu, em 1957. Meu irmão mais velho, que era advogado, manteve ainda essa alfaiataria por dois ou três anos, para ajudar no sustento da nossa família. Depois passou adiante, veio para o Rio, e cada um dos filhos tomou seu rumo. Quando meu pai morreu eu já estava prestando concurso para o Museu Nacional. 


"Alberto, meu
irmão mais velho,
tinha ascendência
sobre mim e
orientava e
instruía minhas
leituras. Eu lia
escondida os
romances de
Madame Delly,
porque ele achava
aquilo um
desperdício e eu
não queria
aborrecê-lo"

"Alberto, meu tinha ascendência sobre mim e orientava e instruía minhas leituras. Eu lia escondida os romances de Madame Delly, porque ele achava aquilo um desperdício e eu aborrecê-lo"

\section{Sua mãe ajudava o seu pai na loja?}

Era dona-de-casa e também trabalhava muito na loja, era um braço do negócio. Tinha um tipo mignon, muito delicada, muito gentil. Não conseguia dizer um nome pejorativo, mas era bastante enérgica quando acompanhava o meu pai no trabalho.

Seus pais estimulavam os filhos a estudar?

Muito. Eles compraram um piano, nem sei como. Eu e minha irmã tínhamos curiosidade de tocar música. Ela estudou um pouco mais do que eu e chegou a fazer escola de música. Eu tentei mas não dava para a coisa. Depois disseram que eu tinha que estudar violino e chegaram a alugar um. Tive uma professora em Realengo, que acabei convencendo de que estava perdendo o seu tempo.

A senhora não gostava do piano?

Não, eu não tinha um bom ouvido e não conseguia tocar só para agradar pai e mãe. Parei com aquilo e fui fazer o ginásio.

\section{Onde?}

No Ginásio Arte e Instrução, em Cascadura, que era particular. Como éramos quatro irmãos, tínhamos desconto na mensalidade da escola. Eu tinha feito o primário numa escola pública em Realengo; depois o científico eu fiz no Colégio Pedro II, no centro do Rio.

\section{Por que a senhora escolheu o científico?}

Eu já tinha uma certa tendência para as ciências. Nas nossas casas sempre teve jardim e quintal com muitas plantas, e me interessei naturalmente por cuidar delas.

A senhora teve um bom ensino de ciências?

Sim, no científico tive bons professores e então me inclinei para isso. Terminei esse curso e quis fazer história natural. Alberto, meu irmão mais velho, tinha ascendência sobre mim e orientava e instruía minhas leituras. Eu lia escondida os romances de Madame Delly ${ }^{7}$, porque ele achava aquilo um desperdício e eu não queria aborrecê-lo. Eu falava que eu poderia ler o que ele queria, mas também ler o que eu quisesse. Aos domingos, quando os jornais tinham mais notícias, ele lia e gostava que eu lesse e comentasse. Ele teve muito cuidado com a gente.

O seu irmão Alberto fez direito?

Sim, foi um excelente advogado, muito conhecido e respeitado. O Maury foi para a Marinha, fez engenharia civil. 


\section{E Odete?}

A Odete fez vestibular para medicina, mas não quis continuar. Casou-se e tornou-se uma boa dona-de-casa. Os três filhos, ainda pequeninos, ela levava para fazer cursos de inglês e de francês. Ela conduziu a educação deles com a mesma orientação que recebemos em nossa casa.

O que seu pai achou da sua decisão de estudar história natural?

Ele não falou nada. O meu irmão adorou, foi assistir aos exames. Quase toda a família apoiou.

\section{A Faculdade Nacional de Filosofia e o Museu Nacional}

"Minha mãe cuidava muito dos jardins. Eram maravilhosas aquelas rosas vermelhas. Fui sedimentando esse gosto. Logo que entrei na faculdade, matava umas aulas chatas e ia para o curso de letras ... e ali assisti às aulas do Manuel Bandeira. Era um privilégio!"
Em que ano a senhora fez o vestibular?

Eu entrei na Faculdade Nacional de Filosofia em 1949 e me formei em 1953. Não fiz o preparatório.

\section{A senhora conhecia o curso do Instituto La-Fayette ${ }^{8}$ ?}

Conhecia, mas a Faculdade Nacional de Filosofia era uma referência, uma ponte importante.

\section{Conhecia alguém que havia feito História Natural?}

Não conhecia ninguém, optei espontaneamente pelo curso. Minha mãe cuidava muito dos jardins. Ela tinha um canteiro grande, só de rosas. Eram maravilhosas aquelas rosas vermelhas, lindas. Fui sedimentando esse gosto. Mas logo que entrei na faculdade, matava umas aulas chatas e ia para o curso de letras. Eu tinha uma prima que fazia esse curso, e ali assisti às aulas do Manuel Bandeira. Era um privilégio!

Qual era a organização curricular do curso de história natural?

Havia as disciplinas básicas: botânica geral, geologia, zoologia, mineralogia, citologia, paleontologia e genética, que era uma cadeira específica da maior importância. O titular dela era Lagden Cavalcante, professor famoso. A genética sempre foi uma matéria chamativa, por sua origem e desenvolvimento. É fantástica! Outras também tinham sua importância, como a geologia, mas mineralogia era chata e petrografia, para quem gostava, era boa; geralmente eu trocava estas por aulas no curso de letras. Física e matemática eram cursos amplos, muito puxados.

\section{Havia mulheres no corpo docente?}

A professora de genética, Deise Falcão, que depois virou titular da cadeira. Tinha também uma professora de zoologia. 
“Tinha muito mais mulheres do que homens. Eram mais ou menos 27 por sala e destes, 13 ou 14 eram homens. Isso era um padrão"

"Eu trabalhava na
ilha dos Macacos.
Era uma doçura
subir aquilo ... eu
ia duas ou três
vezes por semana.
Preparava uma
marmita para
comer lá e, uma
vez, ela ficou mal
embalada ... e os
macacos correram
atrás de mim
como loucos"

"Eu trabalhava na ilha dos Macacos. Era uma doçura subir aquilo ... eu ia duas ou três vezes por semana. Preparava uma marmita para comer lá e, uma vez, ela ficou mal embalada ... e os atrás de mim como loucos"

\section{E entre os alunos?}

Tinha muito mais mulheres do que homens. Eram mais ou menos 27 por sala e destes, 13 ou 14 eram homens. Isso era um padrão.

\section{Esses homens se formaram e foram para onde?}

Não sei para onde foram. Talvez uns dois ou três deles tenham se formado.

Mesmo com toda a importância da genética, quando a senhora começou o curso de história natural já queria fazer botânica?

Ah! sim. Comecei, aliás, fazendo um estágio em Manguinhos, ainda estudante, com Lejeune de Oliveira ${ }^{9}$, que trabalhava na ilha dos Macacos $^{10}$. Era uma doçura subir aquilo, com os macacos atrás de você; eu ia duas ou três vezes por semana. Preparava uma marmita para comer lá e, uma vez, ela ficou mal embalada, começou a exalar o cheiro das frutas e os macacos correram atrás de mim como loucos. Abri a marmita, comecei a jogar as frutas e eles se acalmaram. Cheguei na sede e não havia sobrado nada, o pessoal riu de mim.

\section{Por que a senhora foi procurar o Lejeune?}

Tinha dúvida se queria mesmo fazer algo em zoologia. Quem me indicou o Lejeune foi o Mello Leitão ${ }^{11}$, professor de zoologia da Faculdade de Filosofia. Fiz o estágio e desisti. Uma colega de curso, muito amiga minha, chamada Gisele Machline, já estagiava no Museu Nacional com um grupo de ecologistas coordenado por Fernando SegadasVianna. Quando estávamos no último ano da faculdade, ela nos convidou, eu e Wilma Ormond, para estagiarmos, e eu aceitei. Era uma oportunidade de verificar se era mesmo o que eu queria. Fui e não saí mais do Museu. Larguei as estrelas do mar que estava estudando lá na ilha dos Macacos e comecei o estágio sem remuneração, no laboratório da Divisão de Botânica. Aprendi a lidar com o herbário, com plantas secas, procurava aprender a identificar plantas com ajuda de microscópio e lupa. Tudo sob a orientação dessa grande figura que foi o Fernando; ele era o chefe da Divisão e coordenava o grupo de ecologistas.

\section{Havia outras mulheres?}

Éramos cinco mulheres; depois só ficaram três.

Quem eram elas?

Eu, Wilma Ormond, Zélia Lopes da Silva, Gisele Machline e Isolda Rocha e Silva. A Isolda e a Zélia saíram. 
"Larguei as estrelas do mar que estava estudando lá na ilha dos Macacos e comecei o estágio sem remuneração, no laboratório da Divisão de Botânica. Aprendi a lidar com o herbário, com plantas secas, procurava aprender a identificar plantas com ajuda de microscópio e lupa"
Por quê?

A Isolda foi para a zoologia. A Zélia prestou um concurso para o IBGE: foi trabalhar na mesma área, só que em outra instituição.

\section{Havia outras mulheres na Divisão de Botânica?}

Sim, Ida de Vattimo, que era botânica e também trabalhava com o Segadas. Havia ainda Alceu Magnanini, Sebastião de Oliveira e Silva e Walter Edler, que fizeram concurso para o Jardim Botânico e saíram do Museu.

\section{Por que eles saíram?}

Surgiu uma oportunidade de concurso, de efetivação. Todos os que foram para o Jardim Botânico eram casados e precisavam de estabilidade.

Não havia a carreira de pesquisador no Museu Nacional?

Só mais tarde. Fizemos o concurso em 1957 para o cargo de naturalista. Foi um concurso difícil, com provas, trabalhos de campo, entrevistas. Só depois, com a reforma da Universidade em 1968, foi que o Museu ganhou estrutura acadêmica. ${ }^{12}$

A equipe de estagiários não era remunerada?

No início não, mas depois o Segadas conseguiu um auxílio substancial do CNPq para uma pesquisa muito grande de ecologia, na região de Cabo Frio, e houve bolsas para todos nós.

\section{O Fernando Segadas-Vianna ajudou na preparação para o concurso de natu- ralistas?}

Ele nos preparou e se empenhou muito nesse concurso. Para a Divisão de Botânica foram quatro. Quando fundaram o Instituto de Biologia na Universidade, ele foi para lá, coordenar o Departamento de Ecologia, e eu e Wilma ficamos no Museu.

A senhora não quis acompanhá-lo?

Não me interessei em sair. Eu tinha apego e apreço enormes pelo Museu, pela forma como nos era permitido conduzir o trabalho com liberdade. O Museu é um núcleo muito interessante. Tem botânica em todas as áreas, zoologia em todas as áreas, antropologia em todas áreas - antropologia física, lingüística, antropologia social -, tem paleontologia, geologia, mineralogia. Ter tudo isso a sua volta é muito enriquecedor. É uma congregação de pessoas que interagem, ensinam e aprendem ao mesmo tempo. Essa convivência intensa nos prendeu ao Museu ao longo da vida. Criamos nossa independência também: Fernando foi embora e seguimos as nossas vidas. Participa- 
"Eu tinha apego e apreço enormes pelo Museu, pela forma como nos era permitido conduzir o trabalho com liberdade" mos do Instituto de Biologia dando aula na graduação, mas não saímos do Museu. Vivemos nele a nossa vida profissional e a vida não profissional.

Quem estava na direção do Museu Nacional, na época do concurso? Heloísa Alberto Torres ${ }^{13}$.

O Jardim Botânico não era um lugar atraente para uma estudante de botânica estagiar?

Era, mas surgiu o convite para cá. O Jardim Botânico naquela época era mais dirigido para a sistemática, e eu queria um lastro maior, um campo maior. E a ecologia ainda estava na minha cabeça.

A ecologia era um campo emergente no Brasil?

Havia uma abertura enorme para estudar as áreas vegetais. E nós não estudávamos só as plantas, mas todas as características da região em que ela estava localizada. Coletávamos as plantas como um taxonomista, mas tínhamos outra visão. O resultado desse nosso trabalho em Cabo Frio foi publicado nos Arquivos do Museu Nacional.

No Brasil, além do grupo do Museu, alguém mais trabalhava com essa abordagem?

Em Recife fizeram alguns estudos de campo com uma abordagem mais experimental. O Instituto de Botânica de São Paulo tinha um grupo muito ativo em fisiologia vegetal, cuja figura principal era o grande botânico Luiz Fernando Labouriau ${ }^{14}$. Mas essa abordagem, de integração maior do ambiente verde, foi o Museu que inaugurou: o Segadas a formulou e nós colaboramos estreitamente. Fizemos todo o levantamento da flora do Sudeste, do litoral e da restinga. Ficamos acampados em Cabo Frio durante seis meses.

Como a família reagiu a essa aventura?

Eu estava fazendo estágio, ganhando uma bolsa, não teve problema. Mas no meio acadêmico isso foi espetaculoso, sair assim para Cabo Frio, de caminhão...

Quantas pessoas participaram?

Umas 15 pessoas, mas éramos poucas mulheres: eu, Wilma, Gisele e Zélia. Mais o Segadas, o Jadiehl Loredo Junior e o pessoal de apoio. Nós coletamos muito material de toda a restinga, que hoje está depositado no herbário do Museu Nacional. Foi fantástico.

Por que o interesse pela região de Cabo Frio?

Porque é uma região de restinga muito curiosa. Há a restinga de praia, que é uma faixa, e depois a restinga interna, que se prolonga até 
"A Heloísa me falava que eu seria chefe da Divisão e eu tremia. Quando ela saiu, José Cândido, que assumiu a direção, me chamou e disse que eu seria a chefe. Eu disse que não queria, mas depois acabei aceitando" encontrar uma mata de restinga. Nessa restinga interna, onde nós trabalhamos muito, havia moitas e espaços vazios, o que é sui generis. Ela apresentava um desenvolvimento diferente, era muito complexa. As restingas são diferentes ao longo do litoral brasileiro.

Os trabalhos eram apresentados em congressos?

Sim, eles foram apresentados em congressos de botânica.

E nesses congressos era grande a presença de mulheres?

Sempre; muitas mulheres.

A que sociedade científica vocês se reportavam?

À Sociedade de Botânica, que tinha uma revista, os Anais da Sociedade de Botânica, que publica os trabalhos do congresso.

Chegaram a fazer parte da diretoria dessa sociedade?

Não, nós apresentávamos os trabalhos nos congressos e fizemos parte da presidência de mesa.

A senhora freqüentava a Academia Brasileira de Ciências? Em algum momento teve interesse em ser uma acadêmica?

Freqüentei muito a Academia, participava das sessões, assistia às palestras. Tive vontade de ingressar, mas não ingressei.

A Academia era um lugar muito masculino, não era?

Sim, era muito masculino.

Quem assumiu o laboratório de ecologia quando o Fernando foi para o Instituto de Biologia?

Eu e Wilma. Nós não fomos chefes, mas assumimos as nossas pesquisas, até mesmo antes de o Fernando se afastar do Museu. Tínhamos autonomia.

Como a senhora chegou a chefe de Divisão de Botânica?

Por indicação. A Heloísa me falava que eu seria chefe da Divisão e eu tremia. Quando ela saiu, José Cândido ${ }^{15}$, que assumiu a direção, me chamou e disse que eu seria a chefe. Eu disse que não queria, mas depois acabei aceitando. Eu assumi em 1969 e fiquei quase dez anos.

\section{Quem a senhora sucedeu, na chefia da Divisão?}

O professor Vidigal Sampaio, botânico, um típico naturalista, ou seja, um pesquisador que só coletava plantas, um sistemata. Eu e outros classificávamos para ele. Dava um tremendo trabalho, mas não era ruim, porque para se fazer boa ecologia é preciso muito trabalho metódico com as plantas. Eu gostava mais de experimentação, de 
"Para se fazer boa ecologia é preciso muito trabalho metódico com as plantas. Eu gostava mais de experimentação, de trabalho de campo, como o que fiz sobre $o$ microclima em Cabo Frio, que adorei" trabalho de campo, como o que fiz sobre o microclima em Cabo Frio, que adorei. Era um trabalho penoso, mas eu gostava. Foi muito bem aceito, pois não havia estudos a esse respeito. Depois voltei a estudar germinação, desenvolvimento das sementes.

\section{A senhora mudou de tema?}

Sim, de microclima para as sementes.

Essa mudança foi influenciada pela saída do professor Segadas-Vianna? O Segadas ainda estava lá quando isso ocorreu. Eu comecei com microclima em Cabo Frio. O projeto tinha vários subprojetos: um deles era o microclima e outro era sobre sementes, que não foi adiante porque o grupo era pequeno. Acontece que o trabalho com microclima é muito penoso. Você tem que estar no campo na hora certa, quase de madrugada, para fazer as observações... Enfim, eu dependia sempre de companhia. No acampamento, o Jadiehl ia comigo para as estações, porque eu tinha medo e também porque precisava de ajuda. Quando terminamos o projeto, vi que não poderia continuar desenvolvendo aquele tipo de trabalho, por demandar uma infra-estrutura muito grande. Como eu já tinha certa simpatia por sementes - sempre tive -, prossegui só com isso. Eu já conhecia o Labouriau, amigo da minha família, e resolvi procurá-lo. Ele era muito bom para desenvolver técnicas de estudo de sementes. Aí me fixei nesse tema e voltei-me para as cactáceas da restinga.

\section{Por que as cactáceas?}

Porque tinha uma população muito variada. Bati os olhos nelas e senti que tinha relevância ali. Comecei a coletá-las, mas o Museu não tinha um laboratório equipado com câmaras de germinação, que me permitiriam realizar trabalhos experimentais com controle de luz, temperatura etc. Mesmo assim, comecei a fazer experiências de laboratório e percebi que algumas sementes de cactáceas germinavam tanto no claro quanto no escuro e outras, só em uma dessas condições. Cataloguei e fichei todas aquelas sementes, peguei um avião e fui para o laboratório do Labouriau em Brasília, muito bem equipado. Fiz todo o trabalho experimental com ele, e os resultados coincidiram com os que eu havia obtido aqui, sem amparo técnico da câmara. Mas eu poderia ter esbarrado em resultados falsos, trabalhando com os recursos que eu tinha no Museu, por isso a exigência da câmara. 
"Lancei-me de cabeça na reorganização do herbário. Milhares de plantas ficavam em latas guardadas em armários, muitas sem identificação e sem origem. De nada adianta guardar uma planta sem etiqueta, é jogar fora o trabalho de coleta"
E como chefe da Divisão de Botânica, quais foram suas principais realizações?

Lancei-me de cabeça na reorganização do herbário. Milhares de plantas ficavam em latas guardadas em armários, muitas sem identificação e sem origem. De nada adianta guardar uma planta sem etiqueta, é jogar fora o trabalho de coleta. Fizemos então um modelo de etiqueta para a coleta, nos mesmos moldes do trabalho de Cabo Frio. Todo o departamento colaborou nessa organização. Havia outro problema: cada família botânica tinha um processo administrativo, porque emprestávamos muitas plantas em regime de permuta. Esses processos ficavam no departamento administrativo do Museu e isso dificultava o controle de empréstimos e devoluções. A diretoria concordou em transferir esse arquivo para o Departamento, fizemos um mutirão para reavermos tudo o que estava fora, instituímos novos procedimentos para entrada e saída das plantas e com isso recuperamos grande parte do herbário. Foi uma grande tarefa.

Qual o tamanho do herbário?

Da ordem de milhares de plantas, com os fichários taxonômico, o de localização geográfica e o de autor. Esse trabalho estava atrasadíssimo. Tive a maior satisfação da fazer esse trabalho. Levava os processos para casa e encaixava as fichas.

Ao assumir a chefia da Divisão de Botânica, a senhora abandonou o trabatho de pesquisa?

Não, mas ele foi um pouco prejudicado.

Quais as outras medidas tomadas pela a senhora à frente da Divisão? Tentei trazer gente para aumentar o contingente de pessoal e melhorar as condições de instalação, com salas para cada professor. Foi também construído um novo prédio para o horto.

O Museu dispunha de recursos para isso?

A Universidade era mais generosa do que é hoje.

A senhora gerenciava o orçamento?

Não, mas tive os recursos que precisei.

A senhora conseguiu trazer pesquisadores de fora?

Sim, sempre trazia.

Alguma outra mulher chefiou a Divisão de Botânica?

Quando eu estava na chefia, a Wilma era a minha substituta, e depois foi chefe. Ela foi também coordenadora da Pós-graduação depois de mim. 
A senhora saiu do país para estudos?

Não. Tive vontade, mas nunca saí. Estagiei em Brasília e em São Paulo, no Instituto de Botânica, com o Labouriau.

\section{Na direção do Museu Nacional}

Nos anos 1980 a senhora assumiu a direção do Museu Nacional. Como se deu essa passagem para a área administrativa?

Fui vice-diretora do Museu durante a gestão do Luiz Emygdio ${ }^{16}$, de 1977 até 1980, quando seu mandato expirou. Depois disso, porque a Universidade queria fazer coincidir as eleições de diretores com a do reitor, fui nomeada diretora pro tempore e permaneci no cargo até dezembro de 1981. E de 1986 a 1989 fui diretora titular do Museu.

"Antes de
assumirmos essa
parceria, eu e Luiz
Emydgio nos
relacionávamos
muito pouco. Ele
era um
taxonomista
muito
importante, era
paisagista
também, um
homem muito
preparado"

"Antes de parceria, eu e Luiz Emydgio nos relacionávamos muito pouco. Ele era um nomista uito paisagista mbém, um preparado"

\section{Luiz Emydgio convidou-a para ser vice-diretora?}

Não, foi uma indicação da Congregação do Museu Nacional, formada por cerca de 20 pessoas, entre professores titulares, chefes de departamento e representantes dos professores. Antes de assumirmos essa parceria, eu e Luiz Emygdio nos relacionávamos muito pouco. Ele era um taxonomista muito importante, era paisagista também, um homem muito preparado. Nós nos demos muito bem. Ele deixava a direção, uma grande parte de tempo, sob minha responsabilidade, porque viajava muito.

\section{Mas em 1986 a senhora foi eleita diretora.}

Sim, e fui a mais votada na lista tríplice que o Museu apresentou. Mas antes dessa, houve outra eleição a que me candidatei e também fiquei em primeiro lugar, mas não entrei. Foi escolhido o segundo lugar da lista, Henrique Millan ${ }^{17}$, da Geologia e Paleontologia. Disseram, na época, que o reitor não me indicou porque tinha alguma diferença comigo, que não sei qual era.

Podemos deduzir então que a senhora era muito querida. Afinal foi a mais votada em duas eleições. A que a senhora atribui isso? Gosta da atividade administrativa?

Sou uma pessoa muito tolerante, não sou afobada para tomar decisões, tenho bom senso. Era comum as pessoas dizerem: "Tem que ser a Leda, com aquela capacidade de tolerância e de saber a hora certa de decidir." O Museu me cercou, eu não tive saída e então aceitei. Mas eu queria ter sido diretora quando fui bloqueada. Fiquei danada. Mas tudo bem, quando fui diretora me saí bem. Hoje encontro com colegas na rua e eles falam: "Minha diretora!" 
Como era a relação com a Universidade? Ela liberava recursos para o Museu?

Fazíamos um projeto de despesas com pessoal, equipamentos etc. e mandávamos para a Universidade. Aí, vinham os cortes. Mas tive muito apoio do reitor Horácio Macedo. Consegui mais verbas para contratar serviços de terceiros, o que me permitiu ampliar o corpo de jardineiros, serventes e auxiliares de laboratório. Consegui colocar uma secretária em cada departamento, contratei pessoal para o Serviço de Museologia, reformei os banheiros, fiz obras no horto 'de baixo'. Tudo isso com o apoio da Universidade. O Museu sempre teve, também, convênios com instituições estrangeiras que o supriam bem, como por exemplo a Fundação Rockefeller, que praticamente sustenta a área de antropologia social.

\section{Como foi sua atuação como diretora do Museu Nacional?}

"Tive que observar o Museu em si, pensar na sua estrutura, na sua manutenção. Consegui, por exemplo - o que me deu muita satisfação - a restauração da Sala doTrono"
Tive que analisar todos os projetos dos departamentos, para ver em que podia colaborar. Tive que observar o Museu em si, pensar na sua estrutura, na sua manutenção. Consegui, por exemplo - o que me deu muita satisfação -, a restauração da Sala do Trono. O Museu tem duas salas lindas, essa e a Sala dos Embaixadores. Não sei se hoje elas abrigam alguma exposição, mas naquela época eram mantidas vazias ou com exposições temporárias, só para visitação. A Sala do Trono estava fechada, totalmente descaracterizada, com infiltrações, e consegui uma verba do Ministério da Cultura para sua restauração. Quem a fez foram os técnicos do Patrimônio Histórico, porque o prédio é tombado. Promover essa restauração me satisfez muito. Melhorei a Sala dos Embaixadores e melhorei as exposições, todas compostas de material natural, pertencente às coleções. Instituí a entrada paga, que antes era grátis, afinal era preciso angariar recursos para a manutenção do Museu. Quando chovia, eram goteiras por todos os lados. Em muitas salas consegui mudar as estruturas de madeira dos tetos por estruturas metálicas.

Como a senhora conseguiu realizar tudo isso?

O Darcy Ribeiro estava no Ministério, e ele havia sido da Antropologia do Museu por muito tempo.

A atividade administrativa tem uma importante dimensão política, e a senhora parece ter muita habilidade nesse domínio.

Tenho sim. Sempre tive muita penetração no Museu. É uma instituição pequena mas com muito conteúdo, tem gente de muito valor e conhecimento, e eu gostava de visitar os departamentos, conversar com os professores. Talvez por isso eu tenha ficado tão conhecida. Não sou muito comunicativa, sou muito séria, sisuda. 


\section{“Promover essa restauração me satisfez muito. Melhorei a Sala dos Embaixadores e melhorei as exposições, todas compostas de material natural, pertencente às coleções. Instituí a entrada paga, que antes era grátis"}

\section{"Na pesquisa eu poderia ter ido além do que fui; recuei antes do que devia. $\mathrm{Na}$ administração não poderia dar mais do que dei"}

Ao sair da direção do Museu, em 1989, a senhora voltou para o laboratório? Não, porque eu já não tinha mais estagiária. Ela entrou como professora auxiliar, depois foi efetivada.

Que motivos a levaram a se aposentar, em 1994?

Eu estava cansada. Mas gostava tanto do Museu - e gosto ainda que continuei freqüentando o horto. Não na minha especialidade, porque já não havia aquela antiga estrutura e não quis pedir bolsa ao CNPq, pois isso implicava compromisso. Eu vinha duas vezes por semana e ajudava a Wilma, a Pós-graduação, discutia programas. Depois tive perdas na família que me derrotaram muito e parei de ir ao Museu.

Como a senhora avalia a sua trajetória como pesquisadora e administradora? O que lhe deu mais satisfação, do ponto de vista pessoal?

As duas atividades me deram satisfação. Acho que na pesquisa eu poderia ter ido além do que fui; recuei antes do que devia. Na administração não poderia dar mais do que dei, tanto que fui indicada duas vezes para a diretoria. Assumi a direção por insistência do pessoal, eu já não queria. Eu quis ser diretora na primeira vez que me candidatei e o meu nome foi recusado, aquele era o meu momento. Mas fiquei satisfeita com o meu trabalho na direção e o pessoal do Museu também ficou.

\section{As mulheres no Museu Nacional}

O Museu Nacional tem muitas mulheres. A botânica é área de grande concentração feminina?

Acho que sim. O Serviço de Museologia também é só de mulheres.

Na sua opinião, porque que a botânica concentra tantas mulheres? Todo botânico é bom, todo jardineiro é bom. A mulher é muito delicada, é atraída pelas plantas, seduzida pelo aroma. É uma atividade delicada: o trabalho no microscópio, com as pinças, limpando com um pincelzinho a planta. Até os desenhos de iconografia botânica eram feitos por uma maioria de mulheres.

O Jardim Botânico tinha essa mesma tendência?

Também; as mulheres eram em maior número.

A senhora nos disse que já no vestibular sua opção pela botânica estava definida.

Sim, eu achava que era um trabalho leve e agradável. 
Mas com as excursões, a senhora certamente percebeu que as atividades de botânica não têm nada do que se entende como feminino. Na verdade, parece haver um ideário social que atribui a essa profissão um caráter feminino, por exigir habilidades atribuídas às mulheres.

É, eu tinha uma imagem meio romântica. Mas nada disso é verdade. Mesmo o taxonomista trabalha muito no campo. Ele chega carregado de plantas, tem que prensar, secar, preparar tudo aquilo. Qualquer excursão, mesmo nos arredores da cidade, é muito trabalhosa. Levase o dia inteiro para coletar uns frutinhos, anda-se muito, sem falar no trabalho de registro no diário de campo.

Quando a senhora ingressou no Museu, em 1953, também havia mais mulheres?

Não; os homens eram maioria.

"A mulher é muito delicada, é atraída pelas plantas, seduzida pelo aroma"

\section{"A maioria das mulheres da Botânica não casou. O Museu é solteirão"}

As mulheres que trabalhavam no Museu eram casadas? O casamento, a maternidade eram considerados empecilhos para o trabalho delas?

Não. Tinha muita mulher solteira no Museu, mas não sei se era devido à carreira. Eu não casei, Wilma e Zélia também não. Na Antropologia, muitas mulheres não casaram. A maioria das mulheres da Botânica não casou. O Museu é solteirão.

No Museu Nacional, a senhora conviveu com a antropóloga Heloísa Alberto Torres e com Bertha Lutz, da Zoologia. Pode nos falar sobre elas?

Heloísa era diretora quando ingressei no Museu. Era uma mulher bonita, poderosa, mandona, mas ao mesmo tempo muito gentil. Eu gostava muito dela e ela de mim. Era preparada, culta, de bons relacionamentos.

Sabemos que ela enfrentou muitas crises internas, na direção do Museu Nacional. A senhora percebia alguma resistência pelo fato de ela ser mulher?

Houve muitas crises, mas não por ela ser mulher. Heloísa saiu devido a uma crise com uns professores que eram grandes nomes da zoologia: Newton Dias dos Santos ${ }^{18}$, José Oiticica ${ }^{19}$, Haroldo Travassos ${ }^{20}$, era uma turma de combate. Eles queriam tirar a Heloísa, porque entendiam que a direção dela já tinha se esgotado e era preciso renovar o Museu. Daí surgiu uma crise, mas não a acompanhei porque era nova no Museu, e o assunto não me interessava muito, na época.

\section{E Bertha Lutz?}

Ela estava na banca do meu concurso e me fez um elogio tão grande, foi tão afetiva e gentil. Eu gostava muito dela, muito mesmo. Quando eu estava me preparando para o concurso, meu pai faleceu, mas fui 


\section{"Heloísa Alberto Torres era diretora quando ingressei no Museu. Era uma mulher bonita, poderosa, mandona, mas ao mesmo tempo muito gentil" \\ "A Bertha tinha sido deputada, lutava pelo voto, pela liberdade e expressão da mulher. Eu gostava de conversar com ela sobre esses temas"}

até o fim da seleção. Fiz um relatório de trabalho de campo, ela gostou muito e escreveu um documento para mim. Apesar de eu estar vivendo um momento difícil, não acho que ela tenha feito aquilo para me consolar; acho que foi sincero, foi pelo meu desempenho no concurso. Eu procuro esse relatório e o documento dela, mas infelizmente não o acho mais. A Bertha era uma figura! Andava com uns cachorros - seu carro tinha umas telas de arame - e ela os trazia sempre ao Museu. Sentava com eles no escritório, e o pessoal reclamava. Eu compreendia.

\section{E o trabalho científico dela?}

Ela trabalhava com batráquios. Coletou muitas espécies novas e isso é da maior importância. Não havia ninguém fazendo esse tipo de trabalho. Ela o fazia sozinha, não tinha estagiário. Acho que era muito exigente, impaciente com alunos. Arranjei uma assistente para ela que ficou uns dois anos e foi embora.

\section{A senhora conhecia a atuação feminista de Bertha Lutz?}

Claro. Ela tinha sido deputada, lutava pelo voto, pela liberdade e expressão da mulher. Eu gostava de conversar com ela sobre esses temas. Ela contava as lutas... Eu saía do meu canto na Botânica e ia para a sala dela. Eu me sentava na sua cadeira de balanço e ela começava a conversar sobre o afeto e amor que tinha pelo pai, os cachorros, as excursões, os bichos que tinha no laboratório... Foi uma lutadora a quem devemos muito.

\section{Ela nunca the falou por que se envolveu com essa causa?}

Nunca abordei esse assunto. Hoje, pensando no tempo em que convivemos, acho que eu devia ter explorado mais as conversas com ela. Eu a escutava falar e não perguntava muito. Tinha pouca experiência para 'invadir' a Bertha Lutz.

A senhora era jovem, e o movimento feminista dos anos 50 foi bem mais tímido do que o ocorrido nos anos seguintes.

As mulheres não estavam à flor da pele, não lutavam.

Desde que se instituíram, em 1968, os departamentos em substituição às cátedras, há relatos de professoras universitárias que se sentem injustamente preteridas nos processos de ascensão de carreira. A senhora observou situações como essa no Museu, após ele ter sido reestruturado nos moldes acadêmicos?

Não percebi nada disso. 
E a senhora, enfrentou algum tipo de discriminação de seus colegas, ainda que de modo sutil?

Nunca. Pelo contrário; as mulheres aqui tiveram muita classe. Nas reuniões da Congregação - quando fui diretora pude presenciar e acompanhar isso - ninguém se intimidava. Era um debate aberto de idéias, homens e mulheres se expressavam igualmente, sem problemas.

\section{$\rightarrow \rightarrow-x<r$}

Ficha técnica da entrevista

Local da entrevista: Rio de Janeiro

Data: abril de 2004

Duração: 5 horas

Entrevistadores: Nara Azevedo, Bianca Antunes Cortes, Magali Romero Sá

Edição: Bianca Antunes Cortes.

\section{NOTAS}

${ }^{1}$ Este depoimento integra o acervo constituído pelo projeto Gênero e Ciência: Carreira e Profissionalização no Instituto Oswaldo Cruz, Museu Nacional e Instituto de Biofísica (1939-1968), realizado na Casa de Oswaldo Cruz entre 2003-2006, com financiamento do CNPq e do Programa da Fiocruz de Apoio à Pesquisa Estratégica em Saúde (Papes).

${ }^{2}$ O trabalho, um estudo ecológico e fitossocial das plantas da família das tifáceas, foi defendido na Wayne University, em Detroit, Michigan, e publicado em 1951 no The Journal of Ecology (Segadas-Vianna, 1951).

${ }^{3}$ Ver Correspondência administrativa, ofícios 884 (28/9/1945), 909 (3/10/1945), 1004 (9/11/1845) e 1117 (26/12/1945) (Arquivo Histórico do Museu Nacional, Rio de Janeiro).

${ }^{4}$ Conforme Olympio da Fonseca Filho (1974, p.121-122), esses primeiros discípulos do mestre canadense abririam novas linhas de pesquisa em ecologia vegetal, em suas respectivas instituições.

${ }^{5}$ Ver, ao final, as referências dos trabalhos que Pierre Dansereau publicou em parceria com SegadasVianna em 1947, 1948 e 1952.

${ }^{6}$ Quanto ao substrato e à vegetação, Dansereau reconheceu três estágios sucessionais na vegetação litorânea: as que sofrem influência de água salgada (halosere); as que possuem influência de água doce (limnosere) e as que ocorrem em ambientes secos (xerosere) (Sonehara, 2005, p.15).

${ }^{7}$ Dau refere-se à Coleção Biblioteca das Moças, publicada no Brasil pela Companhia Editora Nacional (São Paulo) entre as décadas de 1940 e 1960 e muito popular entre o público jovem feminino. Um casal de irmãos franceses, sob o pseudônimo M. Delly, era autor de vários títulos de sucesso dessa coleção (Cunha, 1998).

${ }^{8}$ O Instituto La-Fayette foi criado em 1916 e dedicava-se, inicialmente, ao ensino comercial e ao ensino técnico de agrimensura e topografia, química industrial, mecânica e eletricidade prática. Em 1944 deu início às atividades de ensino superior, com a criação da Faculdade de Filosofia, Ciências e Letras, uma das escolas que deram origem, em 1950, à Universidade do Distrito Federal, atual Universidade do Estado do Rio de Janeiro (UERJ).

${ }^{9}$ Lejeune Pacheco Henriques de Oliveira, pesquisador da Seção de Hidrobiologia do Instituto Oswaldo Cruz nas décadas de 1940 e 1950, liderou importantes estudos no campo da liminologia e, sob a direção 
de Olympio da Fonseca Filho, ministrou curso de hidrobiologia. Desenvolveu também estudos sobre a poluição de lagoas litorâneas no estado do Rio de Janeiro.

${ }^{10} \mathrm{Na}$ época, funcionava na ilha dos Macacos, ou ilha do Pinheiro, a Seção de Hidrobiologia do Instituto Oswaldo Cruz, uma estação de estudos em biologia marinha que encerrou suas atividades nos anos 1960. Nessa mesma década, durante o Projeto Rio, do governo federal, a ilha foi aterrada para urbanização do Complexo da Maré.

${ }^{11}$ Cândido Firmino Mello Leitão (1886-1948) formou-se em medicina pela Faculdade de Medicina do Rio de Janeiro. Foi professor de zoologia na Escola Superior de Agricultura e Medicina Veterinária, em Niterói, e no Instituto de Educação, ambos no estado do Rio de Janeiro. Foi ainda zoólogo do Museu Nacional e presidente da Academia Brasileira de Ciências (1943-1945).

${ }^{12}$ O Museu Nacional esteve vinculado ao Ministério da Agricultura até 1930, quando passou ao Ministério da Educação e Saúde. Em 1937, com a criação da Universidade do Brasil, foi a ela subordinado, e em 1941 voltou a vincular-se ao Ministério de Educação e Saúde. Nesse momento sofreu algumas reformas de estrutura, suas seções foram denominadas divisões e o botânico Luiz Emydgio de Mello Filho foi designado chefe da Divisão de Botânica. Em 1946 o Museu foi reintegrado à Universidade do Brasil.

${ }^{13}$ Uma das pioneiras da antropologia no Brasil, a carioca Heloísa Alberto Torres (1895-1977) ingressou no Museu Nacional como assistente de Roquette-Pinto em 1918, tornou-se professora substituta da Divisão de Antropologia em 1925 e dirigiu a instituição de 1938 a 1955. Intelectual ativa no meio político-administrativo do país, destacam-se sua participação na criação do Serviço de Patrimônio Hstórico e Artístico Nacional, em 1937, o qual dirigiu no mesmo ano; seu envolvimento na criação do Instituto Internacional da Hiléia Amazônica, que, embora não tenha se concretizado, acabou por dar origem ao Instituto Nacional de Pesquisas Amazônicas; e a presidência do Conselho Nacional de Proteção ao Índio (1959-1967). Igualmente importante foi sua atuação em defesa dos direitos da mulher, a exemplo das relações que manteve com a Liga Internacional de Mulheres Pró Paz e Liberdade e a Federação Brasileira Pelo Progresso Feminino. Sua residência em Itaboraí (RJ) foi transformada em centro cultural em 1995 e abriga parcela significativa de seu acervo pessoal. (cf. www.unicamp.br/pagu/heloisa_alberto_torres/texto_ornellas.pdf, acessado em 15 fev. 2008.

${ }^{14}$ Luiz Fernando Gouvêa Labouriau (1921-1996) ingressou em 1941 na Escola Naval. Sem ter definido ainda sua profissão, freqüentou como estagiário o Museu Nacional e o Instituto Oswaldo Cruz. Trabalhou também no Jardim Botânico do Rio de Janeiro. Graduou-se e obteve o título de mestre em botânica na Universidade de Michigan e doutorou-se em fisiologia vegetal no Instituto de Tecnologia da Califórnia, onde também trabalhou. Dedicou-se ao estudo dos efeitos do fotoperiodismo e da termoperiodicidade na formação de esporângios em samambaias, a problemas de fisiologia ecológica e ao fenômeno da germinação das sementes, assunto em que é conhecido internacionalmente.

${ }^{15}$ José Cândido de Mello Carvalho (1914-1994) formou-se na Escola Superior de Agricultura de Viçosa. Em 1940 concluiu o mestrado em zoologia na Universidade de Nebrasca e, dois anos depois, o doutorado na Universidade de Iowa. Entomólogo especializado na família Miridae, ingressou no Museu Nacional em 1946, quando realizou um grande trabalho de campo no Xingu. Com a criação do Instituto de Pesquisas Amazônicas (INPA), em 1955, foi nomeado diretor do Museu Paraense Emílio Goeldi. Foi diretor do Museu Nacional de 1956 a 1961.

${ }^{16}$ Luiz Emygdio de Mello Filho, botânico, chefe da Divisão de Botânica e diretor do Museu Nacional de 1976 a 1980.

${ }^{17}$ José Henrique Millan foi diretor do Museu Nacional entre 1982 e 1985.

18 Newton Dias dos Santos foi aluno da primeira turma de história natural da Escola de Ciências da Universidade do Distrito Federal. Em 1940 formou-se em medicina pela Universidade do Brasil. Entre 1948 e 1953 foi colaborador do jornal A Manhã, no suplemento dominical Ciência Para Todos. Zoólogo, foi diretor do Museu Nacional de 1961 a 1964.

${ }^{19}$ Filho do pensador anarquista José Oiticica, nasceu em 1906 no Rio de Janeiro. Era pai do artista plástico Hélio Oiticica e do arquiteto César Oiticica. Formou-se na Escola Nacional de Engenharia, no Rio de Janeiro. Foi professor de matemática e ciências nos colégios Jacobina, Pedro II e na Faculdade Nacional de Medicina. Trabalhou com entomologia no Museu Nacional. Sócio do Foto Clube Brasileiro e de outras associações de fotografia, foi presença constante nas mostras do Rio de Janeiro e de São Paulo. Teve várias fotos premiadas em exposições e concursos internacionais. Morreu em 1964.

${ }^{20}$ Filho do helmintologista Lauro Travassos, Haroldo ingressou no Museu Nacional nos anos 1940, onde desenvolveu estudos sobre os peixes de água doce no Brasil. Entre outros trabalhos publicou, em 1960, o Catálogo dos peixes do Vale do São Francisco. 


\section{REFERÊNCIAS BIBLIOGRÁFICAS}

CUNHA, Maria Teresa Santos.

Mulheres e romances: uma intimidade radical.

Cadernos Cedes, Campinas, v.19, n.45.

Disponível em: http://www.scielo.br. Acesso em: abr. 2008. 1998.

DANSEREAU, Pierre; SEGADAS-VIANNA, Fernando.

Ecological study of the peat bogs of Eastern North America, 1: structure and evolution of vegetation. Canadian Journal of Botany, Ottawa, v.30, n.4, p.490-520. 1952.

DANSEREAU, Pierre; SEGADAS-VIANNA, Fernando.

Les principales associations et la succession dans les tourbières de la province de Québec. Annales de l'ACFAS, Montreal, v.14, p.83-84. 1948.

\section{DANSEREAU, Pierre; SEGADAS-VIANNA,}

Fernando.

The high mountain vegetation of Southeastern Brazil. Bulletin of the Ecological Society of America, Washington, v.28, n.4, p.48. 1947.

DAU, Leda.

Microclimas das restingas do Sudeste do Brasil, 1: restinga interna de Cabo Frio. Archivos do Museu Nacional, Rio de Janeiro, v.50. 1960.

FONSECA FILHO, Oympio da.

A Escola de Manguinhos: contribuição para o estudo do desenvolvimento da medicina experimental no Brasil. São Paulo: Empresa Gráfica. Separata do tomo II de Oswaldo Cruz Monumenta Histórica. 1974.
ORMOND, Wilma.

Ecologia das restingas do Sudeste do Brasil: comunidades vegetais das praias arenosas, parte 1. Archivos do Museu Nacional, Rio de Janeiro, v.50. 1960.

SEGADAS-VIANNA, Fernando.

Phytosociological and ecological study of cattail stands in Oakland county, Michigan. The Journal of Ecology, London, v.39, n.2, p.316329. 1951.

SEGADAS-VIANNA, Fernando; ORMOND, Wilma; DAU, Leda (Ed.).

Flora ecológica de restingas do Sudeste do Brasil. 23 v. Rio de Janeiro: Museu Nacional. 1965-1978.

SHTEIR, Ann B.

Gender and 'modern' botany in Victorian England. Osiris, Chicago, v. 12, p.29-38. 1997.

\section{SLACK, Nancy G.}

Nineteenth-century American women botanists: wives, widows and work. In: AbirAm, Pnina; Outram, Dorinda (Ed.). Uneasy careers and intimate lives: women in science (1789-1979). New Brunswick: Rutgers University Press. p.77-103. 1989.

SONEHARA, Juliano de Souza

Aspectos florísticos e fitossociológicos de um trecho de vegetação de restinga no Parque estadual do rio da Onça - Matinhos, PR. Dissertação (Mestrado) - Curso de Pós-graduação em Botânica,

Universidade Federal do Paraná, Curitiba. 2005. 